Received: 29 May 2018

Accepted: 18 July 2018

Published online: 09 August 2018



C N IF
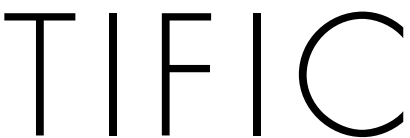

REP

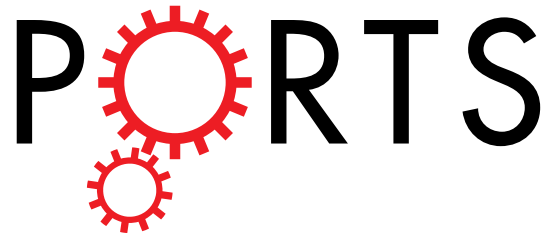

OPEN

\title{
The Role of Nano-domains in $\{\overline{1} 011\}$ Twinned Martensite in Metastable Titanium Alloys
}

\author{
Sangwon Lee, Chanhee Park, Jaekeun Hong (iD \& Jong-taek Yeom
}

The formation mechanism of $\{\overline{1} 011\}_{\alpha^{\prime}}$ type twinned $\alpha^{\prime}$-martensitic structures was investigated in titanium alloys, and in-depth characterizations of the microstructures were performed using scanning electron microscopy and transmission electron microscopy. The randomly distributed nano-domains nucleated by water quenching were sheared during the primary martensite transformation. Experimental results revealed that this sheared nano-domain interferes with the primary martensite transformation and induces a secondary martensite transformation. In terms of crystallography, the secondary martensite transformed from the sheared nano-domain has a $\{\overline{1} 011\}_{\alpha^{\prime}}$ type twin relationship with the primary martensite. The growth of both martensites yielded a more twinned martensitic structure as the applied strain increased.

The martensitic transformation greatly influences the mechanical properties of titanium alloys. There are two martensitic transformation in Ti alloys: $\beta \rightarrow \alpha^{\prime}$-martensite (hexagonal structure) and $\beta \rightarrow \alpha^{\prime \prime}$-martensite (orthorhombic structure). The $\alpha^{\prime}$-martensite transformation is observed in relatively lean alloy systems. There are two kinds of morphologies for $\alpha^{\prime}$-martensite: lath-type and plate-type martensite. The lath-type $\alpha^{\prime}$-martensite consists of bundles of parallel fine plate martensite. The boundaries of $\alpha^{\prime}$-martensite within the bundles are low angle dislocation boundaries ${ }^{1}$. As the solute content increases, transition of the $\alpha^{\prime}$-martensite morphologies occurs from bundles of $\alpha^{\prime}$-martensite to individual large plate $\alpha^{\prime}$-martensite (plate-type martensite) ${ }^{2,3}$. Some plate-type $\alpha^{\prime}$-martensites have $\{\overline{1} 011\}_{\alpha^{\prime}}$ type internal twins which originate from $\{110\}_{\beta}{ }^{3}$. In highly alloyed systems, the structure of $\alpha^{\prime}$-martensite becomes distorted and orthorhombic $\alpha^{\prime \prime}$-martensite is formed during quenching.

Previous studies reveal that (1) the impingement of secondary martensite to primary martensite and (2) the lattice invariant deformation generates $\{\overline{1} 011\}_{\alpha^{\prime}}$ type internal twins ${ }^{1,4}$. The formation of $\{1011\}_{\alpha^{\prime}}$ type internal twins is dependent on the composition. For example, the fraction of primary martensit that contain $\{\overline{1} 011\}_{\alpha^{\prime}}$ type internal twins increased as the $\mathrm{Cr}$ content increases to $5.5 \%$ in $\mathrm{Ti}$-Cr binary system ${ }^{4}$. Even though the generation of internal twins is believed to accommodate the transformation strain ${ }^{5}$, the reason that internal twinning is observed only in relatively high alloy systems showing plate-type martensite is still unclear. The existing crystallography theory of the twinned martensitic transformation can not explain the dependence of composition ${ }^{4}$.

Ti-Nb-based Gum metal has been recently developed, which shows extraordinary mechanical properties including low elastic modulus, excellent cold ability, superelasticity and invar-like behaviour ${ }^{6-9}$. Tahara et al. ${ }^{9}$ reported that $\mathrm{Ti}-\mathrm{Nb}$ exhibits a stress-induced martensite transformation while $\mathrm{Ti}-\mathrm{Nb}-\mathrm{O}$ suppress this transformation and promotes superelasticity behaviour. They noted that $\mathrm{Ti}-\mathrm{Nb}-\mathrm{O}$ contains nano-sized modulated structures which could affect the unique properties of Ti-Nb-based Gum metal, and suggested that these could originate due to the relaxation of oxygen local strain caused by $\{110\}\langle 1 \overline{1} 0\rangle_{3}$ shuffling.

Martensite is related to the $\{11 \overline{2}\}\langle 111\rangle_{\beta}$ shear (lattice distortion) followed by $\{110\}\langle 1 \overline{1} 0\rangle_{\beta}$ shuffle (lattice modulation). If only $\{110\}\langle 1 \overline{1} 0\rangle_{\beta}$ shuffling occurs, the nanodomain $\left(\mathrm{O}^{\prime}\right)$ with six shuffling modes can be generated ${ }^{10}$. $\mathrm{O}^{\prime}$ has orthorhombic symmetry (lattice parameters $\mathrm{a}=0.317 \mathrm{~nm}, \mathrm{~b}=0.448 \mathrm{~nm}$ and $\mathrm{c}=0.448 \mathrm{~nm}$ ). The shear of $\{11 \overline{2}\}\langle 111\rangle_{3}$ in $\mathrm{O}^{\prime}$ can induce the martensite transformation, but only two martensite variants are possible for one shuffling mode. $\mathrm{O}^{\prime}$ is therefore known to suppress the martensitic transformation ${ }^{9,10}$. Zheng et al. ${ }^{10,11}$ investigated the effects of substitutional atom addition on the generation of $\mathrm{O}^{\prime}$. As the alloying content $(\mathrm{Al}, \mathrm{Zr}, \mathrm{Sn})$ increased, $\{110\}\langle 1 \overline{1} 0\rangle_{\beta}$ displacement becomes more favourable than $\{11 \overline{2}\}\langle 111\rangle_{\beta}$ displacement, resulting in $\mathrm{O}^{\prime}$ promotion even when the oxygen content is low.

Titanium Alloys Department, Metal Materials Division, Korea Institute of Materials Science (KIMS), Changwon, 51508, Republic of Korea. Correspondence and requests for materials should be addressed to S.L. (email: geegee@ kims.re.kr) 
(a)

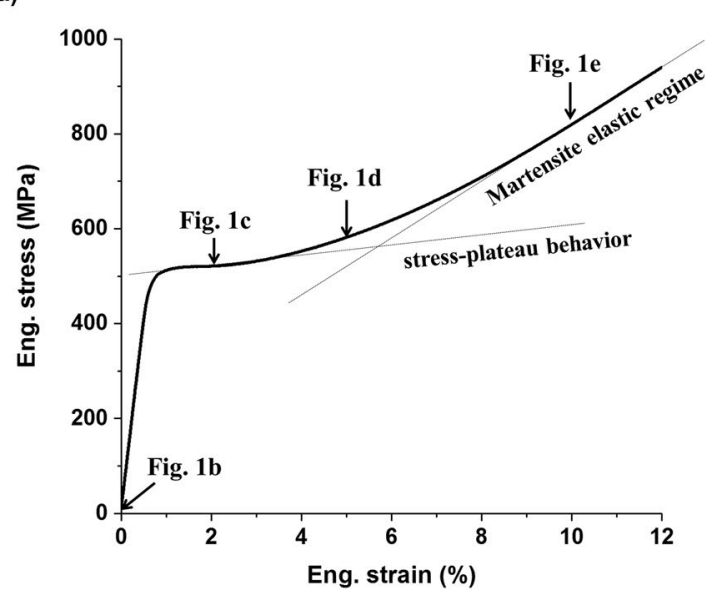

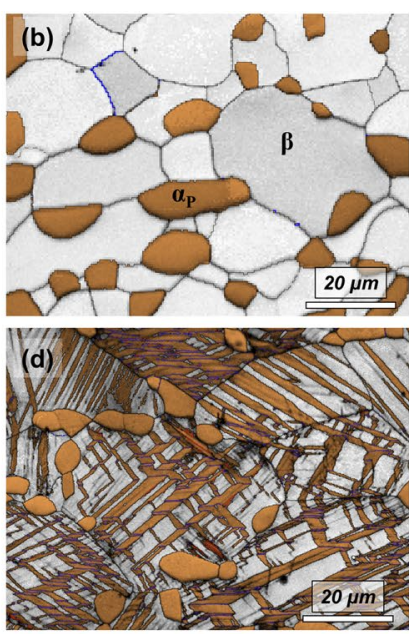

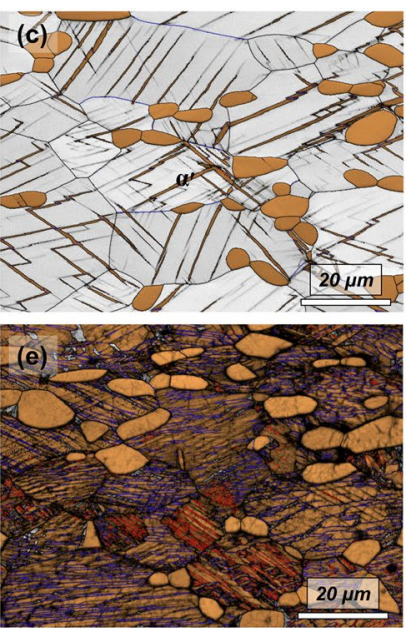

Figure 1. (a) Tensile behaviour of Ti-4Al-4Fe-0.25Si-0.1O alloy. Strain dependence of EBSD phase maps of $\mathrm{Ti}-4 \mathrm{Al}-4 \mathrm{Fe}-0.25 \mathrm{Si}-0.1 \mathrm{O}$ alloy strained to $(\mathbf{b}) 0 \%$, (c) $2 \%$, (d) $5 \%$ and (e) $10 \%$. The blue and red boundaries of martensite are corresponded to twin and Burgers relationship, respectively.

Recently, Ti-4Al-4Fe-0.25Si-0.1O alloy has been developed for reduced production cost and enhanced mechanical properties compared to Ti- $6 \mathrm{Al}-4 \mathrm{~V}^{12,13}$. The alloy is in relatively high alloyed system compared to others showing the lath type martensite transformation like pure $\mathrm{Ti}^{4}$ and $\mathrm{Ti}-1 \mathrm{Cu}^{1}$. This alloy is metastable resulting in the $\alpha^{\prime}$-martensite transformation after quenching from $950{ }^{\circ} \mathrm{C}^{12}$. As the quenching temperature was decreased, the quenching-induced martensite transformation was inhibited because of an increase of $\beta$ stability caused by a Fe partitioning from primary $\alpha$ to $\beta^{13}$. Fe is strong $\beta$ stabilizer element. In this condition, the strain or stress-induced $\alpha^{\prime}$-martensitic transformation occurred with the generation of $\{\overline{1} 011\}_{\alpha^{\prime}}$ type internal twins. Thus $\mathrm{Ti}-4 \mathrm{Al}-4 \mathrm{Fe}-0.25 \mathrm{Si}-0.1 \mathrm{O}$ is a very suitable alloy for the study of plate type $\alpha^{\prime}$-martensite because it exhibit various $\alpha^{\prime}$-martensite transformation mechanism. In this study, we also found $\mathrm{O}^{\prime}$ in the $\beta$ phase for water-quenched $\mathrm{Ti}-4 \mathrm{Al}-4 \mathrm{Fe}-0.25 \mathrm{Si}-0.1 \mathrm{O}$ (wt.\%). We noted that there is a special relationship between $\mathrm{O}^{\prime}$ and twinned martensitic structures. We carefully investigated the microstructure of Ti-4Al-4Fe- $0.25 \mathrm{Si}-0.1 \mathrm{O}$ by scanning electron microscopy (SEM) and transmission electron microscopy (TEM). Evidence that the internal twins originate due to $\mathrm{O}^{\prime}$ is introduced in this study.

\section{Results}

Figure 1a shows the engineering tensile stress-strain curve of quenched Ti-4Al-4Fe-0.25Si-0.1 O. The alloy exhibits stress-plateau behaviour, which is frequently observed in Ti alloys showing stress-induced martensite transformations ${ }^{14-17}$. After stress-plateau behaviour occurs, an elastic deformation of transformed martensite generally occurs. Electron backscattering diffraction (EBSD) phase maps of Ti-4Al-4Fe-0.25Si-0.1 O strained to $0 \%, 2 \%, 5 \%$ and $10 \%$ are shown in Fig. 1b-e, respectively. The microstructure of the un-deformed sample consisted of primary $\alpha\left(\alpha_{p}\right)$ and $\beta$, and there was no trace of athermal martensite. As the applied strain increased, the stress-induced $\alpha^{\prime}$-martensite transformation occurred and its volume fraction increased. The Ti-4Al-4Fe-0.25Si-0.1 O strained to $10 \%$, where it is in the elastic regime of martensite, showing that there is no retained $\beta$.

Figure 2a-c shows EBSD inverse pole figure maps corresponding to Fig. 1c-e. Normally, two variants of $\alpha^{\prime}$-martensite are observed in a $\beta$ grain, the primary variant $\left(\alpha_{p}^{\prime}\right)$ which is directly transformed from $\beta$ and a secondary variant $\left(\alpha_{\mathrm{s}}^{\prime}\right)$ that is nucleated in $\alpha_{\mathrm{p}}^{\prime}$ or at the tip of $\alpha_{\mathrm{p}}^{\prime}$ as shown in Fig. 2a. The misorientation angle (blue line) between $\alpha_{p}^{\prime}$ and $\alpha_{s}^{\prime}$ is $57.22^{\circ}$ which corresponds to a twin relationship, $\{1011\}$ type internal twins ${ }^{18}$. As the applied strain increased, the growth of $\alpha_{\mathrm{s}}^{\prime}$ occurred and it crossed the other laths of $\alpha_{\mathrm{p}}^{\prime}$. The growth direction of $\alpha_{s}^{\prime}$ is different between $\alpha_{p}^{\prime}$ and $\beta$. This resulted in a zig-zag microstructure of martensite as shown in Fig. $2 \mathrm{~b}$. This zig-zag microstructure disappeared at a $10 \%$ strain, because almost all retained $\beta$ was transformed to martensite at this point as shown in Fig. 2c. The microstructure after the strain reached $10 \%$ consisted of $\alpha_{p}$ and twinned $\alpha^{\prime}$-martensite $\left(\alpha_{\mathrm{p}}^{\prime}\right.$ and $\left.\alpha_{\mathrm{s}}^{\prime}\right)$.

TEM observations were carried out to investigate the origin of this twinned martensite. Figure $3 \mathrm{a}-\mathrm{d}$ exhibits several selective area diffraction (SAD) patterns of a $\beta$ grain of quenched Ti-4Al-4Fe-0.25Si-0.1 O. There are additional diffraction spots indicated by the arrows in each diffraction pattern of $\beta$. Even though some spots appear dim, bright and dark-field TEM micrographs clearly show that nano-sized particles $(<10 \mathrm{~nm})$ were nucleated in quenched Ti-4Al-4Fe-0.25Si-0.1 O. The spots of the nano-sized particles correspond to the nano-domain $\left(\mathrm{O}^{\prime}\right)$, which is commonly reported in $\beta$-Ti species such as Ti-Nb based Gum metal ${ }^{9,19}$. Six possible variants of $\mathrm{O}^{\prime}$ are possible depending on the shuffling mode, as shown in Table 1 . The variants of $\mathrm{O}^{\prime}$ are randomly distributed in annealed samples because all variants are energetically equivalent ${ }^{19}$. Figure $3 \mathrm{a}-\mathrm{d}$ shows similar results in that several variants of $\mathrm{O}^{\prime}$ are observed. If an external stress (tensile or cold rolling) is applied to $\mathrm{O}^{\prime}$, preferential growth of an $\mathrm{O}^{\prime}$ variant occurs to release the applied stress ${ }^{19,20}$. This indicates that $\mathrm{O}^{\prime}$ is stress-dependent.

Figure 4a shows a bright-field STEM (scanning transmission electron microscope) image of Ti-4Al-4Fe$0.25 \mathrm{Si}-0.1 \mathrm{O}$ strained to $2 \%$. The electron beam was parallel to the $[100]_{3}$ direction. The diffraction pattern of the 

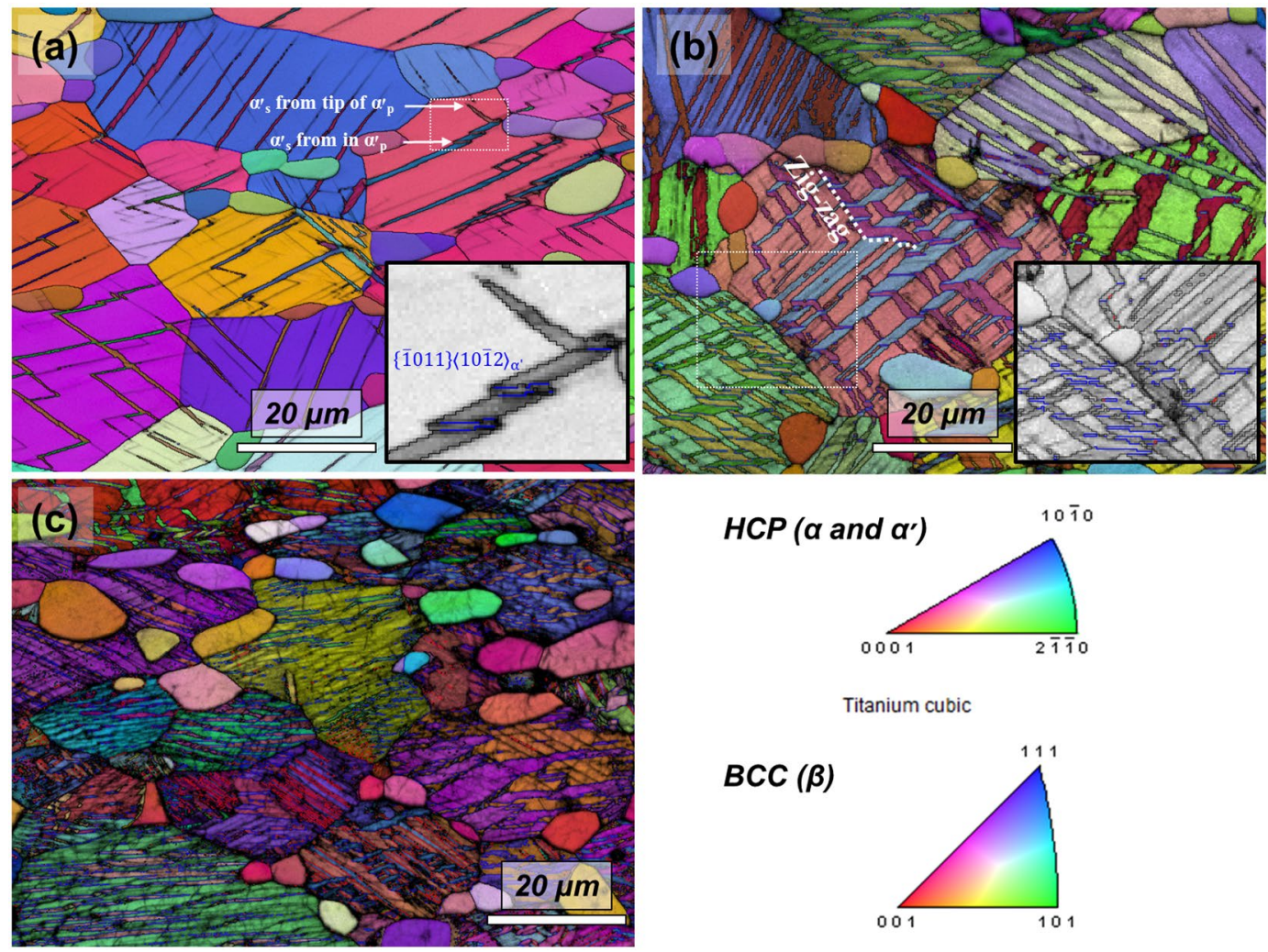

Titanium cubic

$\operatorname{BCC}(\beta)$

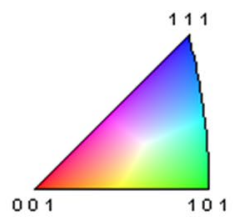

Figure 2. Strain dependence of EBSD inverse pole figure maps (parallel to the tensile direction) of Ti-4Al$4 \mathrm{Fe}-0.25 \mathrm{Si}-0.1 \mathrm{O}$ alloy strained to (a) $2 \%$, (b) $5 \%$ and (c) $10 \%$. The blue and red boundaries of martensite are corresponded to twin and Burgers relationship, respectively.

$\beta$ regime is shown in Fig. $4 \mathrm{~b}$. Two variants of $\mathrm{O}^{\prime}$ which are parallel to the $\langle 100\rangle_{\mathrm{O}^{\prime}}$ direction were observed. The $\mathrm{O}^{\prime}$ spots in the deformed sample are more clearly visible than in the un-deformed sample (Fig. 3a). Two variants of stress-induced $\alpha_{\mathrm{p}}^{\prime}\left(\alpha_{1}^{\prime}\right.$ and $\left.\alpha_{2}^{\prime}\right)$ in $\beta$ were observed. The corresponding diffraction patterns of both $\alpha_{\mathrm{p}}^{\prime}$ as shown in Fig. $4 \mathrm{c}$ reveal that both $\alpha_{\mathrm{p}}^{\prime}$ have $\mathrm{a}\{\overline{1} 011\}_{\alpha^{\prime}}$ type twin relationship. Based on Fig. $4 \mathrm{c}$, the orientation relationships between $\alpha_{1}^{\prime}, \alpha_{2}^{\prime}$ and $\beta$ is

$$
(0 \overline{1} 1)[100]_{\beta} / /(1 \overline{1} 01)[01 \overline{1} 1]_{\alpha^{\prime} 1} / /(1 \overline{1} 01)[\overline{1} 011]_{\alpha^{\prime} 2}
$$

Nishiyama et al. ${ }^{21}$ report that the $\{1011\}_{\alpha^{\prime}}$ type twin plane comes from $\{110\}_{\beta}$ assuming that the habit plane is $\{334\}_{\beta}$ and Burgers orientation relationship hold good in the transformation. However, very few of these two $\alpha_{p}^{\prime}$ in $\beta$ were observed as shown in Figs 1 and 2. In addition, almost all misorientation angle between both $\alpha_{\mathrm{p}}^{\prime}($ the grain boundaries between two $\alpha_{p}^{\prime}$ are indicated by the red lines in Figs 1 and 2) were approximately $63.23^{\circ}$ which corresponds to Burgers relationship ${ }^{18}$. The formation of twinned martensitic structures caused by these two $\alpha_{p}^{\prime}$ should be minor. There are different contrasts in each $\alpha_{p}^{\prime}$ as indicated by the white rectangle in Fig. 2a. Selective diffraction patterns of theses regimes shown in Fig. 4 d,e, exhibiting additional diffraction spots as well as $\alpha_{p}^{\prime}$. Dark-field TEM micrographs of additional spots clearly show that there are nano-sized lines $(<400 \mathrm{~nm})$ in $\alpha_{\mathrm{p}}^{\prime}$ as shown in Fig. 4f,g. In terms of shape, it is similar to the internal twins shown in the magnified section of Fig. $2 a$. In terms of diffraction patterns, the one variant of $\mathrm{O}^{\prime}$ observed in Fig. 4a appears to remain after the martensitic transformation. The crystal structure based on observed diffraction patterns are however neither $\alpha^{\prime}{ }_{s}$ nor $\mathrm{O}^{\prime}$.

\section{Discussion}

$\{11 \overline{2}\}\langle 111\rangle_{3}$ shear (lattice distortion) is necessary to transform the martensite from $\mathrm{O}^{\prime}$. Each variant of $\mathrm{O}^{\prime}$ allows only two of the 12 possible variants of martensite ${ }^{10}$ because of its particular shuffling mode. This is one reason why $\mathrm{O}^{\prime}$ suppresses martensitic transformations. All variants of $\mathrm{O}^{\prime}$ are randomly distributed in annealed Ti alloys ${ }^{19}$. If the martensite transformation occurs in one of variants of $\mathrm{O}^{\prime}$, the other variants of $\mathrm{O}^{\prime}$ will be unfavourable for the transformation because they have different shuffling mode with the martensite. This unfavourable variant of $\mathrm{O}^{\prime}$ could remain in $\alpha^{\prime}$ in the sheared state. To investigate this, we drew an example of crystal structures of $\beta, \alpha_{2}^{\prime}$ and $\mathrm{O}^{\prime}$ as shown in Fig. 5. The Burgers relationship between $\beta$ and $\alpha_{2}^{\prime}$ is present in Fig. 5a. The $\mathrm{O}^{\prime}$ variant which is favourable for the $\alpha_{2}^{\prime}$ transformation is $\mathrm{O}_{4}^{\prime}$ (Table 1). The diffraction spots of $\mathrm{O}_{4}^{\prime}$ overlap with the $\beta$ spots in the $[100]_{3}$ zone axis of Fig. $1 \mathrm{~b}$. In the same manner, the $\mathrm{O}^{\prime}$ variant which is favourable for the $\alpha_{s}^{\prime}$ transformation is $\mathrm{O}_{2}^{\prime}$. The crystallography of $\beta$ and $\mathrm{O}_{2}^{\prime}$ is presented in Fig. 5b. During the $\alpha_{2}^{\prime}$ transformation $\left(=\alpha_{\mathrm{p}}^{\prime}\right.$ transformation), $\mathrm{O}_{2}^{\prime}$ has an unfavourable orientation because the shuffling mode is different. Some $\mathrm{O}_{2}^{\prime}$ could be sheared and become 


\begin{tabular}{|l|l|l|l|l|}
\hline \multirow{2}{*}{ Variants } & \multirow{2}{*}{$\begin{array}{l}\text { Shuffling } \\
\text { direction }\end{array}$} & \multicolumn{4}{|l|}{ Lattice correspondence } \\
\cline { 3 - 5 } & $\mathbf{X}$ & $\mathbf{Y}$ & $\mathbf{Z}$ \\
\hline $\mathrm{O}^{\prime}{ }_{1}$ & $(0 \overline{1} 1)[011]_{\beta}$ & {$[100]_{\beta}$} & {$[011]_{\beta}$} & {$[0 \overline{1} 1]_{\beta}$} \\
\hline $\mathrm{O}^{\prime}{ }_{2}$ & $(011)[0 \overline{1} 1]_{\beta}$ & {$[\overline{1} 00]_{\beta}$} & {$[0 \overline{1} 1]_{\beta}$} & {$[011]_{\beta}$} \\
\hline $\mathrm{O}_{3}^{\prime}$ & $(10 \overline{1})[101]_{\beta}$ & {$[010]_{\beta}$} & {$[101]_{\beta}$} & {$[10 \overline{1}]_{\beta}$} \\
\hline $\mathrm{O}_{4}^{\prime}$ & $(101)[10 \overline{1}]_{\beta}$ & {$[0 \overline{1} 0]_{\beta}$} & {$[10 \overline{1}]_{\beta}$} & {$[101]_{\beta}$} \\
\hline $\mathrm{O}^{\prime}{ }_{5}$ & $(\overline{1} 10)[110]_{\beta}$ & {$[001]_{\beta}$} & {$[110]_{\beta}$} & {$[\overline{1} 10]_{\beta}$} \\
\hline $\mathrm{O}_{6}^{\prime}{ }_{6}$ & $(110)[\overline{1} 10]_{\beta}$ & {$[00 \overline{1}]_{\beta}$} & {$[\overline{1} 10]_{\beta}$} & {$[110]_{\beta}$} \\
\hline
\end{tabular}

Table 1. All nano-domain variants depending on shuffling direction ${ }^{17}$.
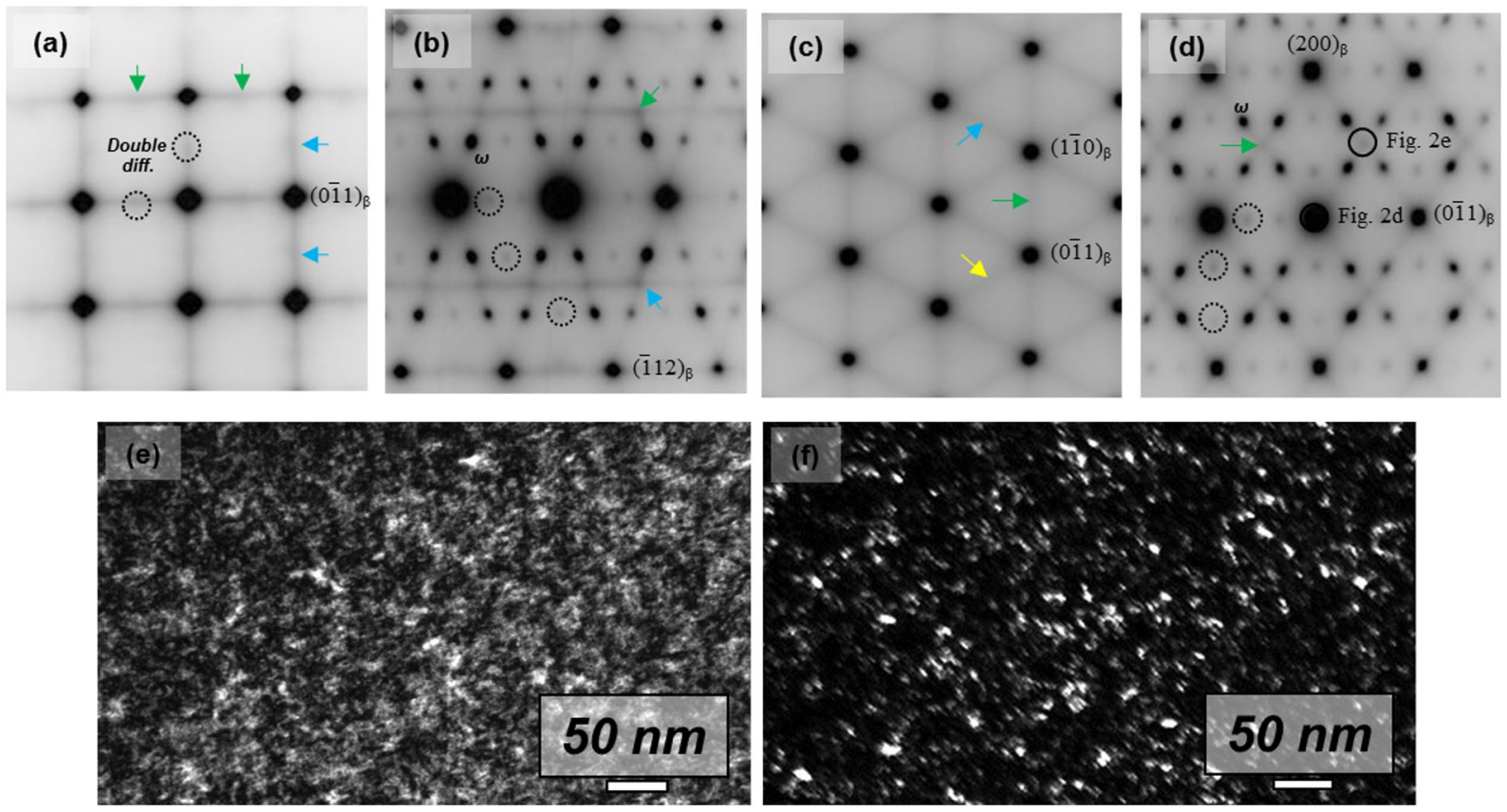

Figure 3. Selected area diffraction patterns of quenched Ti-4Al-4Fe-0.25Si alloy. The electron beam is parallel to $(\mathbf{a})[100]_{\beta},(\mathbf{b})[311]_{3},(\mathbf{c})[111]_{3}$ and $(\mathbf{d})[011]_{3}$. (e) Bright-field TEM micrograph of quenched Ti-4Al-4Fe$0.25 \mathrm{Si}-0.1 \mathrm{O}$ alloy. (f) Corresponding dark-field TEM micrograph showing the nano-domain.

$\mathrm{O}_{\mathrm{s}}^{\prime}$ by $\{11 \overline{2}\}\langle 111\rangle_{3}$ type shearing for the $\alpha^{\prime}{ }_{2}$ transformation, as shown in Fig. $5 \mathrm{c}$. The orientation relationships of Fig. 5 are as follows:

$$
\begin{gathered}
(0 \overline{1} 1)[100]_{\beta} / /(1 \overline{1} 1)[011]_{\mathrm{O}^{\prime} 4} / /(1 \overline{1} 01)[\overline{1} 011]_{\alpha^{\prime} 2} \\
(0 \overline{1} 1)[100]_{\beta} / /(\overline{1} 00)[0 \overline{1} 0]_{\mathrm{O}^{\prime} 2} \\
(\overline{1} 00)[0 \overline{1} 0]_{\mathrm{O}^{\prime} \mathrm{s}} / /(1 \overline{1} 01)[\overline{1} 011]_{\alpha^{\prime} 2}
\end{gathered}
$$

Figure $5 \mathrm{a}-\mathrm{c}$ reveal that $\mathrm{O}_{\mathrm{s}}^{\prime}$ has a triclinic structure (angle $\alpha \neq \beta \neq \gamma$ ). Based on the conventional lattice parameters of $\alpha(\mathrm{a}=0.294 \mathrm{~nm}$ and $\mathrm{c}=0.468 \mathrm{~nm})$, the crystal structure of $\mathrm{O}^{\prime}{ }_{\mathrm{s}}$ was computed as $(\mathrm{a}=0.346 \mathrm{~nm}$, $\mathrm{b}=0.454 \mathrm{~nm}, \mathrm{c}=0.454 \mathrm{~nm}, \alpha=80.71^{\circ}, \beta=86.28^{\circ}$ and $\gamma=86.28^{\circ}$ ). Based on the orientation relationship and computed crystal structure of $\mathrm{O}^{\prime}{ }_{s}$, diffraction patterns were simulated as shown in Fig. 6 . The simulated patterns of Fig. $6 \mathrm{a}-\mathrm{c}$ are consistent with the experimentally measured patterns given in Fig. $4 \mathrm{~b}-\mathrm{e}$.

The selective diffraction pattern of $\beta$ matrix and $\alpha^{\prime}{ }_{2}+\mathrm{O}^{\prime}{ }_{\mathrm{s}}$ regime are shown in Fig. 7a-b respectively, where the specimen is tilted such that electron beam is parallel to the $\langle 311\rangle_{3}$ direction of the matrix. Athermal $\omega$ was additionally observed in the $\beta$ matrix. One thing to note is that diffraction spots of $\omega$ and $\beta$ were also observed in the $\alpha_{2}^{\prime}+\mathrm{O}^{\prime}{ }_{\mathrm{s}}$ regime. The simulated diffraction patterns of $\alpha_{2}^{\prime}, \mathrm{O}^{\prime}{ }_{s}$ and $\beta$ are similar to experimentally measured patterns. The deviation between Fig. 7b,c may be due to the fact that the zone axis of $\beta$ in the $\alpha_{2}^{\prime}+\mathrm{O}^{\prime}{ }_{s}$ regime may be not parallel even though the zone axis of the $\beta$ matrix is accurately parallel to the $\langle 311\rangle_{3}$ direction. Dark-field TEM micrographs of $\mathrm{O}_{S}^{\prime}, \beta$ and $\omega$ (Fig. 8a-c respectively) clearly show that the $\beta+\omega$ regime is present between $\mathrm{O}_{s}^{\prime}$. This un-transformed $\beta+\omega$ regime in $\alpha_{2}^{\prime}$ reveals that different shuffling modes between $\alpha_{2}^{\prime}\left(\right.$ or $\mathrm{O}_{4}^{\prime}$ ) and $\mathrm{O}^{\prime}$ s 



Figure 4. (a) STEM image of Ti-4Al-4Fe-0.25Si alloy stained to $2 \%$. Selected area diffraction pattern of (b) $\beta$, (c) $\alpha_{1}^{\prime}+\alpha_{2}^{\prime}$, (d) $\alpha_{1}^{\prime}$ and (e) $\alpha_{2}^{\prime}$ regime. The electron beam is parallel to [100] $]_{3}$. (f) Dark-field TEM micrograph showing an un-known phase in $(\mathbf{f}) \alpha_{1}^{\prime}$ and $(\mathbf{g}) \alpha_{2}^{\prime}$.

(or $\mathrm{O}_{2}^{\prime}$ ) suppress the $\alpha^{\prime}$-transformation. If the $\beta$ stability is high enough (as in Gum metal), the effect of $\mathrm{O}^{\prime}$ on the martensite transformation can be noticeable. To our knowledge, this is the first experimental evidence that $\mathrm{O}^{\prime}$ suppresses martensitic transformations.

The crystallography of $\alpha_{\mathrm{p}}^{\prime}$ (or $\alpha_{2}^{\prime}$ ) transformed from $\mathrm{O}_{4}^{\prime}$ is presented in Fig. 9a. The $\alpha_{\mathrm{p}}^{\prime}$ had a Burgers relationship. The martensite transformed to $\mathrm{O}_{4}^{\prime}$ could have a Burgers relationship in the same manner (Fig. 9b). Although $\alpha_{p}^{\prime}$ martensite transformation from both $\mathrm{O}^{\prime}$ occur at the same time, the volume of twinned $\alpha_{p}^{\prime}$ structure was small because the $\mathrm{O}^{\prime}$ variant is selected based on the applied stress. Tahara et al. ${ }^{9}$ and Kim et al. ${ }^{19}$ confirmed that variant selection of $\mathrm{O}^{\prime}$ occurs during cold rolling. Liu et al. ${ }^{20}$ showed that tensile loading induced variant selection of $\mathrm{O}^{\prime}$ while compressive loading suppressed $\mathrm{O}^{\prime}$ by means of an in situ high-energy $\mathrm{X}$-ray diffractometer. Figure 4 showed no evidence of the variant selection of $\mathrm{O}^{\prime}$ because the performed pre-strain tests removed the residual stress. The variant-selected $\mathrm{O}^{\prime}$ is returned to the annealed state when the tensile loading is removed ${ }^{20}$. Therefore, the occurrence of variant selection of $\mathrm{O}^{\prime}$ during tensile loading could interfere with the nucleation of $\alpha_{\mathrm{p}}^{\prime}$ with other variants. The internal martensite $\left(\alpha_{\mathrm{s}}^{\prime}\right)$ had a $(\overline{1} 011)_{\alpha^{\prime}}$ type twin relationship with $\alpha_{\mathrm{p}}^{\prime}$. The sheared nano-sized domain $\left(\mathrm{O}_{\mathrm{s}}^{\prime}\right)$ observed in $\alpha_{\mathrm{p}}^{\prime}$ may play a key role in the $\alpha_{\mathrm{s}}^{\prime}$ transformation and formation of the twinned martensitic structure. Figure $9 \mathrm{c}$ shows the crystallography of the possible transformation of martensite from $\mathrm{O}_{s}^{\prime}$. $[110]_{\mathrm{O}^{\prime} \mathrm{s}}$ and $[\overline{1} 01]_{\mathrm{O}^{\prime} \mathrm{s}}$ are parallel to $[2 \overline{1} \overline{1} 0]_{\alpha^{\prime} \mathrm{p}}$ and $[\overline{1} 2 \overline{1} 3]_{\alpha^{\prime} \mathrm{p}}$, respectively. Thus, the $(1 \overline{1} 1)_{\mathrm{O}^{\prime} \mathrm{s}}$ is parallel to the $(\overline{1} 011)_{\alpha^{\prime} \mathrm{p}}$. To have a twin relationship, $(1 \overline{1} 1)_{\mathrm{O}^{\prime} \mathrm{s}}$ and $(01 \overline{1} 1)_{\alpha^{\prime} \mathrm{s}}$ should be parallel each other. Even though the crystal structure of $\mathrm{O}^{\prime}{ }_{\mathrm{s}}$ is not common in the literature, the lattice distance of ' 1 ' and ' 2 ' and angle between ' 1 ' and ' 2 ' in $\mathrm{O}^{\prime}{ }_{s}$ as shown in Fig. $9 \mathrm{c}$ is exactly the same as that of the martensite crystal structure. If the martensite transformation $\left(\alpha_{\mathrm{s}}^{\prime}\right)$ occur from $\mathrm{O}_{s,}^{\prime} \alpha_{s}^{\prime}$ can easily have a twin relationship with $\beta$ through the invariant plane $(1 \overline{1} 1)_{\mathrm{O}^{\prime} \mathrm{s}}$ which minimizes the strain energy

Figure 10 illustrates the procedure of forming twinned martensite in metastable $\beta$ alloys. All variants of nano-sized domains were randomly distributed during quenching. A variant of the nano-sized domain which is favourable to the applied stress induced a variant of the martensite $\left(\alpha_{\mathrm{p}}^{\prime}\right)$ transformation. When the growth of $\alpha_{\mathrm{p}}^{\prime}$ pass through some nano-sized domains which have different shuffling directions with $\alpha_{\mathrm{p}}^{\prime}$, these domains are sheared $\left(\mathrm{O}_{\mathrm{s}}^{\prime}\right)$ and still remain in $\alpha_{\mathrm{p}}^{\prime}$. As the applied strain increased, $\mathrm{O}_{\mathrm{s}}^{\prime}$ is transformed to martensite $\left(\alpha_{\mathrm{s}}^{\prime}\right)$. In terms of crystallography, $\alpha_{s}^{\prime}$ has a twin relationship, $\{1011\} 10 \overline{1} 2_{\alpha^{\prime}}$ with $\alpha_{p}^{\prime}$. The growth of $\alpha_{s}^{\prime}$ occurs and embeds in the retained $\beta$. The different growth directions of $\alpha^{\prime}$ between $\alpha_{p}^{\prime}$ and $\beta$ result in an observed temporary zig-zag martensitic microstructure. As the applied strain increases further, $\beta$ is perfectly transformed to two martensite $\left(\alpha_{s}^{\prime}\right.$ and $\left.\alpha_{p}^{\prime}\right)$, and become a twinned martensitic structure.

Alloying elements change the possibility of $\{11 \overline{2}\}\langle 111\rangle_{\beta}$ shearing and $\{110\}\langle 1 \overline{1} 0\rangle_{\beta}$ shuffling which are necessary for the martensitic transformation ${ }^{14,22}$. For example, $\mathrm{Al}$ and $\mathrm{Zr}$ addition in $\mathrm{Ti}$ - $18 \mathrm{Mo}$ promoted $\{110\}\langle 1 \overline{1} 0\rangle_{\beta}$ shuffling over the $\{11 \overline{2}\}\langle 111\rangle_{3}$, leading to the formation of nano-domains ${ }^{22}$. The variant selection of the nano-domain occurred depending on the stress state ${ }^{9,19,20}$. This selection determine the $\alpha_{p}^{\prime}{ }^{10}$. The present study showed other variants of nano-domain which have different shuffling mode with the $\alpha_{p}^{\prime}$ were sheared in martensite. This provided the nucleation site of twinned $\alpha_{s}^{\prime}$. Namely, the generation of $\{1011\}$-type internal twins in $\alpha_{p}^{\prime}$ is dependent on the composition because the formation of nano-domains is dependent on the alloy composition. If the possibility of $\{11 \overline{2}\}\langle 111\rangle_{\beta}$ shearing is higher than that of $\{110\}\langle 1 \overline{1} 0\rangle_{\beta}$ shuffling, the formation of nano-domains will be 

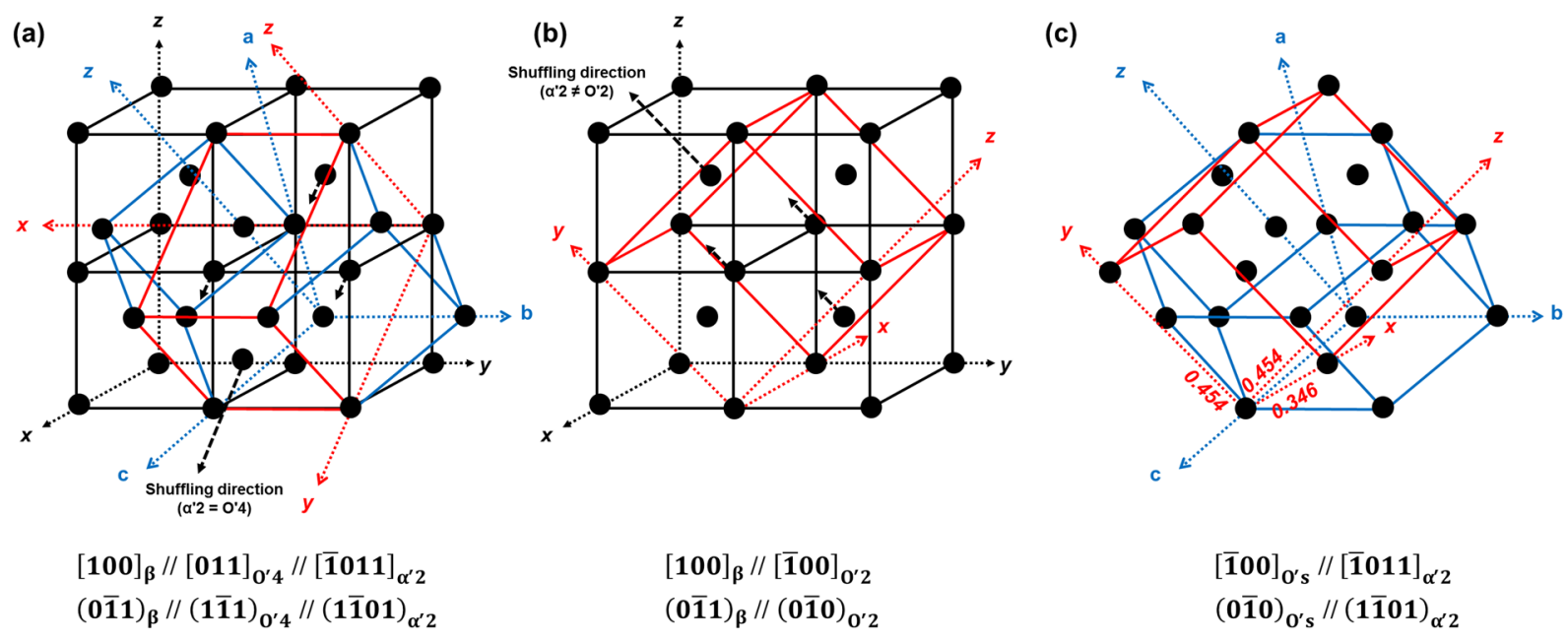

$[\mathbf{1 0 0}]_{\beta} / /[\mathbf{0 1 1}]_{0^{\prime} 4} / /[\overline{\mathbf{1 0 1 1}}]_{\alpha^{\prime} 2}$
$(\mathbf{0 1 1})_{\beta} / /(\mathbf{1 1 1})_{0^{\prime} 4} / /(\mathbf{1 1 0 1})_{\alpha^{\prime} 2}$

$[\mathbf{1 0 0}]_{\beta} / /[\overline{\mathbf{1 0 0 0}}]_{0^{\prime} 2}$
$(\mathbf{0 1 1})_{\beta} / /(\mathbf{0 1 0} 0)_{0^{\prime} 2}$

$[\overline{\mathbf{1} 00}]_{\mathrm{O}^{\prime} \mathrm{s}} / /[\overline{\mathbf{1} 011}]_{\alpha^{\prime} 2}$

Figure 5. A schematic illustration exhibiting lattice correspondence: (a) $\beta+\mathrm{O}^{\prime}{ }_{4}+\alpha^{\prime}{ }_{2}$, (b) $\beta+\mathrm{O}^{\prime}$ and (c) $\alpha_{2}^{\prime}+\mathrm{O}^{\prime}$.



\section{$\beta \quad a \quad 0^{\prime} 4 O^{\prime} 2 \bigcirc O^{\prime} s$}

(a)

(b)

(c)

Figure 6. Simulated diffraction pattern in $[100]_{3}$ zone axis showing (a) $\beta+\mathrm{O}^{\prime}{ }_{4}+\alpha^{\prime}{ }_{2},(\mathbf{b}) \beta+\mathrm{O}_{2}^{\prime}$ and (c) $\alpha_{2}^{\prime}+\mathrm{O}^{\prime}$.

limited resulting in no $\{1011\}$-type internal twins. If this transformation procedure $\left(\beta \rightarrow \mathrm{O}^{\prime} \rightarrow \alpha_{\mathrm{p}}^{\prime}\right)$ occur during quenching, various variants of athermal martensite in a prior $\beta$ grain is expected to have each $\{\overline{1} 011\}$-type internal twins.

In literature studies, nano-domains have been investigated in highly alloyed $\beta$ titanium such as Nb-based Gum metal, Ti-23Nb-2Zr-0.7Ta-1.2O (at.\%) ${ }^{19}$, Ti-24Nb-4Zr-8Sn-0.1 O (wt.\%) ${ }^{20}$ and Ti-26Nb-O (at.\%) ${ }^{23}$. These studies reported that nano-domains affect the characteristic mechanical behaviour of Gum metals. The present work reveals that nano-domains were also observed in relatively lean alloyed and metastable titanium alloys showing an $\alpha^{\prime}$-martensite transformation. The nano-domain in metastable titanium alloy induced the twinned martensitic structure during deformation, and this twinned martensitic structure can greatly affect the mechanical properties of the alloy. For example, many Ti-based shape memory alloys have twinned martensitic structures in their annealed or low deformed states ${ }^{24,25}$. As the applied strain increases, detwinning and reorientation can occur; both of these influence the shape memory effect, superelasticity, and fatigue resistance of the alloy ${ }^{26}$.

In summary, the formation mechanism of twinned martensite caused by nano-domains was investigated by means of transmission electron microscopy and scanning electron microscopy and tensile tests in metastable $\mathrm{Ti}-4 \mathrm{Al}-4 \mathrm{Fe}-0.25 \mathrm{Si}$ alloy. The main conclusions are as follows:

1. Nano-domains were randomly distributed in the quenched alloys. During deformation, a nano-domain which has a variant favourable to the applied stress influenced the primary martensitic transformation. 

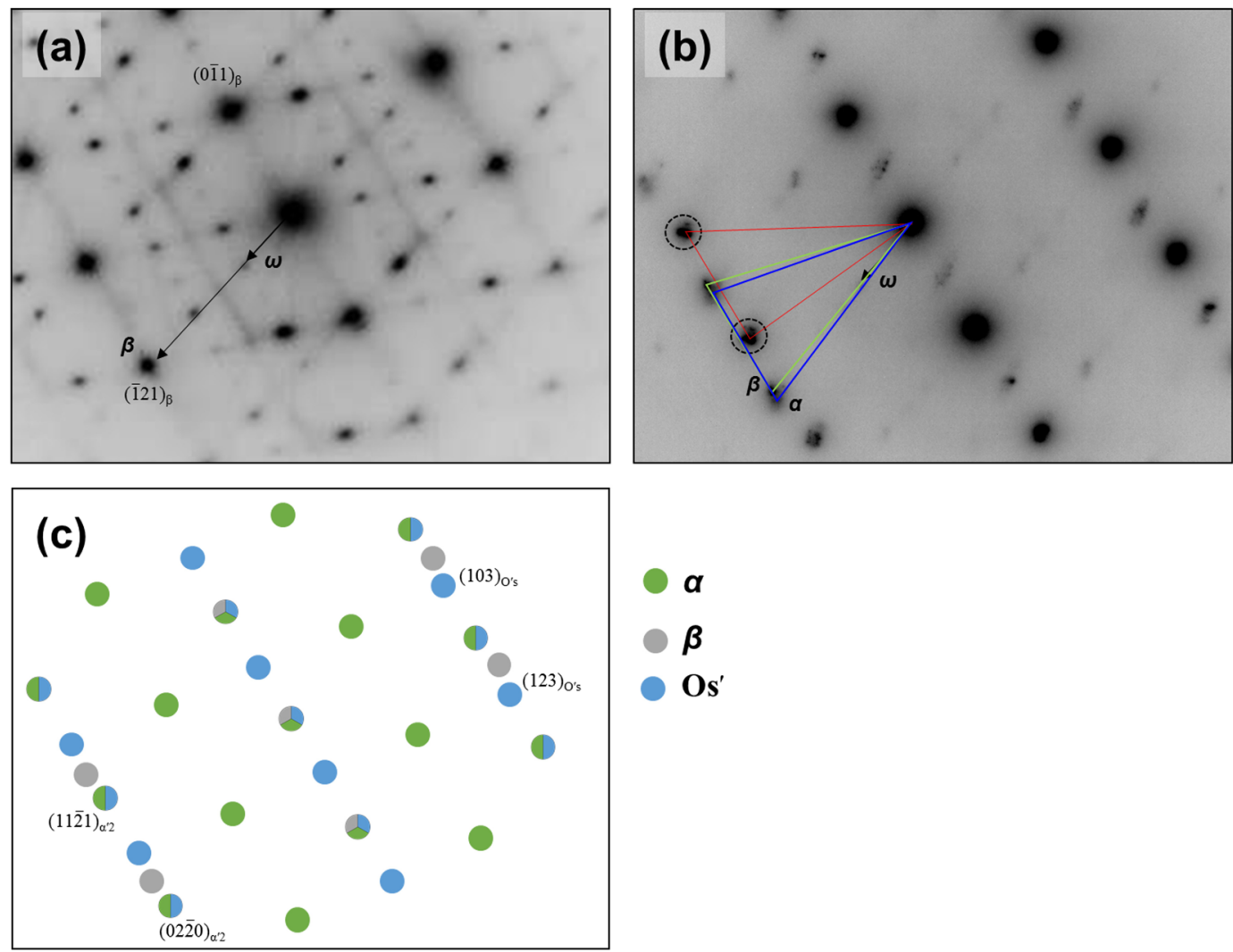

Figure 7. Selected area diffraction patterns of Ti-4Al-4Fe-0.25Si alloy strained to $2 \%$ : (a) $\beta$ and (b) $\alpha^{\prime}{ }_{2}+\mathrm{O}^{\prime}{ }_{s}$ regime. The electron beam is parallel to $[311]_{3}$. Simulated diffraction pattern in $[311]_{3}$ zone axis showing $\alpha_{2}^{\prime}+\mathrm{O}_{\mathrm{s}}^{\prime}+\beta$
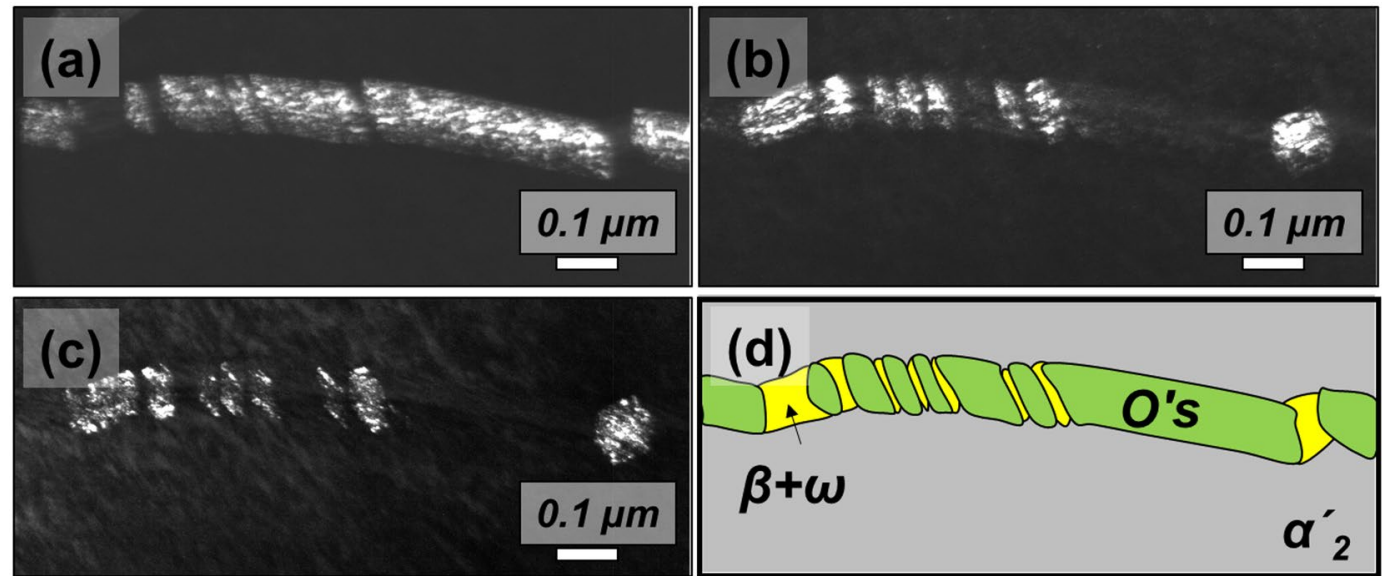

Figure 8. Dark-field TEM micrograph of Ti-4Al-4Fe-0.25Si alloy strained to $2 \%$ showing (a) $\mathrm{O}_{s}^{\prime}$, (b) $\beta$ and (c) $\omega$. (d) Schematic to show the phase constituents in $\alpha_{\mathrm{p}}^{\prime}$.

2. Some nano-domains which had a variant unfavourable to the applied stress were sheared and remained in the primary martensite. Experimental results revealed that these domains interfered with the primary martensitic transformation and partially remained in the $\beta$ in the primary martensite.

3. The sheared nano-domains acted as nucleation sites of the secondary martensite in primary martensite. The secondary martensite has a $\{\overline{1} 011\} 10 \overline{1} 2_{\alpha^{\prime}}$ twin relationship with the primary martensite.

4. As the applied stress increased, both primary and secondary martensite growth were promoted, and twinned martensitic structures were formed. 
(a)

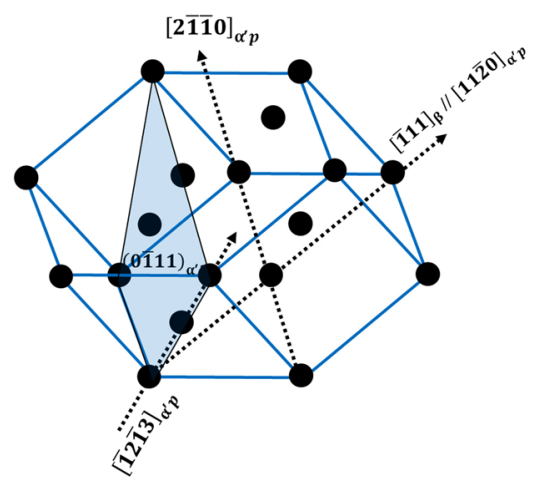

(b)

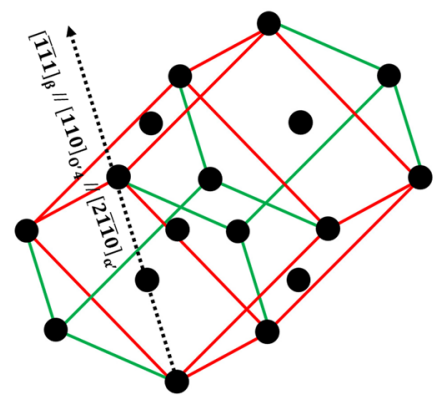

(c)

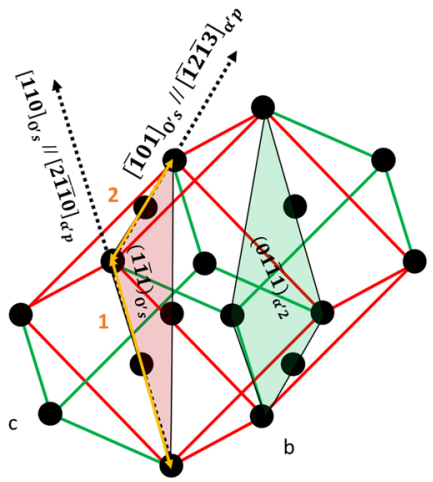

Figure 9. Schematic illustration exhibiting $\alpha^{\prime}$-martensite crystal structure transformed from (a) $\mathrm{O}_{4}^{\prime}$, (b) $\mathrm{O}_{2}^{\prime}$ and $(\mathbf{c}) \mathrm{O}_{s}^{\prime}$.

Increase of applied strain

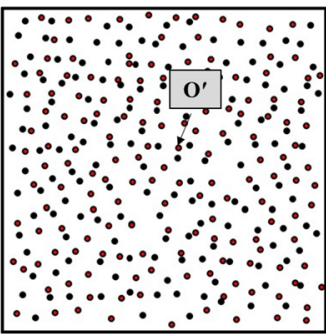

- Randomly distributed $O^{\prime}$



- $\alpha_{\mathrm{p}}^{\prime}$ transformation - Sheared $O^{\prime}\left(O^{\prime} s\right)$ in $\alpha_{p}^{\prime}$



- $\alpha_{\mathrm{p}}^{\prime}$ transformation - $\alpha_{\mathrm{s}}^{\prime}$ transformation from $O^{\prime}$ - Growth of $\alpha_{\mathrm{p}}^{\prime}$ and $\alpha_{\mathrm{s}}^{\prime}$

- Zig-zag martensitic structure

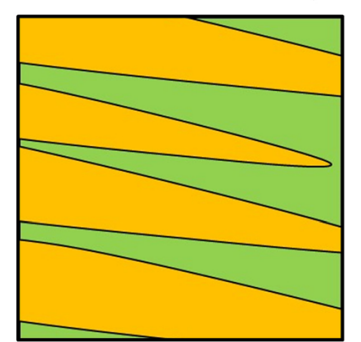

- $\alpha_{p}^{\prime}$ and $\alpha_{s}^{\prime}$ transformation

- Growth of $\alpha_{p}^{\prime}$ and $\alpha_{\text {, }}^{\prime}$

- Twinned structure

Figure 10. A schematic illustration exhibiting the procedure of forming the twinned martensitic structure.

\section{Methods}

The chemical composition of the titanium alloys used in the present work was Ti-4Al-4Fe-0.25Si-0.1 O (wt.\%). Ingots were prepared by vacuum arc melting (VAR) followed by forging in the $\beta$ or $\alpha+\beta$ regimes. The forged alloys were annealed to $880^{\circ} \mathrm{C}$ for $6 \mathrm{~h}$ followed by water quenching. The $\beta$-transus temperature of the alloy was $925^{\circ} \mathrm{C}^{12,13}$. The microstructure of the alloy were observed using a field-emission scanning electron microscope (FE-SEM; JEOL JSM-7100F) equipped with an Aztec EBSD system, and a field-emission transmission electron microscope (FE-TEM; JEOL JEM-2100F). The samples used for FE-SEM were mechanically polished with 400-grit sandpaper to remove surface defects and oxidation and then electropolished at a temperature of $0{ }^{\circ} \mathrm{C}$ in a solution containing $50 \mathrm{vol} \% \mathrm{CH}_{3} \mathrm{OH}+30 \mathrm{vol} \% \mathrm{C}_{4} \mathrm{H}_{9} \mathrm{OH}+20 \% \mathrm{HClO}_{4}$ to remove any products of phase transformation resulting from the mechanical polishing. The sample used for FE-TEM were prepared by a focused ion beam (FIB; FEI Helios Nanolab 650) technique. ASTM E-8 sub-sized tensile specimens (gauge length: $10 \mathrm{~mm}$ and diameter: $2.5 \mathrm{~m}$ ) were tested at $25^{\circ} \mathrm{C}$ with a strain rate of $10^{-3} \mathrm{~s}^{-1}$ in an Instron universal tensile testing machine.

Data availability. The datasets generated during and/or analysed during the current study are available from the corresponding author on reasonable request.

\section{References}

1. Williams, J. C., Taggart, R. \& Polonis, D. H. The Morphology and Substructure of Ti-Cu Martensite. Metall. Trans. 1, 2265-2270 (1970).

2. Zangvil, A., Yamamoto, S. \& Murakami, Y. Electron microscopic determination of orientation. Metall. Trans. 4, 467-475 (1973)

3. Nishiyama, Z. Martensitic Transformation (Academic Press, New York, 1978).

4. Ericksen, R. H., Taggart, R. \& Polonis, D. H. The martensite transformation in Ti-Cr binary alloys. Acta. Metall. 17, 553-564 (1969).

5. Guo, S., Meng, Q., Cheng, X. \& Zhao, X. $\alpha^{\prime}$ martensite Ti-10Nb-2Mo-4Sn alloy with ultralow elastic modulus and high strength. Mater. Lett. 133, 236-239 (2014).

6. Saito, T. et al. Multifunctional Alloys Obtained via a Dislocation-Free Plastic Deformation Mechanism. Science 300, 464-467 (2003).

7. Shin, S., Zhang, C. \& Vecchio, K. S. Phase stability dependence of deformation mode correlated mechanical properties and elastic properties in Ti-Nb gum metal. Mater. Sci. Eng. A 702, 173-183 (2017). 
8. Plancher, E., Tasan, C. C., Sandloebes, S. \& Raabe, D. On dislocation involvement in Ti-Nb gum metal plasticity. Scr. Mater. 68, 805-808 (2013).

9. Tahara, M., Kim, H. Y., Inamura, T., Hosoda, H. \& Miyazaki, S. Lattice modulation and superelasticity in oxygen-added $\beta$-Ti alloys. Acta Mater. 59, 6208-6218 (2011).

10. Zheng, Y. et al. The effect of alloy composition on instabilities in the $\beta$ phase of titanium alloys. Scr. Mater. 116, 49-52 (2016).

11. Zheng, Y., Banerjee, D. \& Fraser, H. L. A nano-scale instability in the $\beta$ phase of dilute Ti-Mo alloys. Scr. Mater. 116, 131-134 (2016).

12. Lee, S. W. et al. Effects of TiFe Intermetallic Compounds on the Tensile Behavior of Ti-4Al-4Fe-0.25Si Alloy. Metall. Mater. Trans. A 48, 561-567 (2017)

13. Lee, S. W., Park, C. H., Hong, J. K. \& Yeom, J.-T. Effect of solution treatment and aging conditions on tensile properties of Ti-Al-Fe-Si alloy. Mater. Sci. Eng. A 697, 158-166 (2017).

14. Kim, H.-S., Lim, S.-H., Yeo, I.-D. \& Kim, W.-Y. Stress-induced martensitic transformation of metastable $\beta$-titanium alloy. Mater. Sci. Eng. A 449-451, 322-325 (2007).

15. Ahmed, T. \& Rack, H. J. Martensitic transformations in Ti-(16-26 at\%) Nb alloys. J. Mater. Sci. 31, 4267-4276 (1996).

16. Li, C., Wu, X., Chen, J. H. \& van der Zwaag, S. Influence of $\alpha$ morphology and volume fraction on the stress-induced martensitic transformation in Ti-10V-2Fe-3Al. Mater. Sci. Eng. A 528, 5854-5860 (2011).

17. Ma, X. et al. Strain rate effects on tensile deformation behaviors of Ti-10V-2Fe-3Al alloy undergoing stress-induced martensitic transformation. Mater. Sci. Eng. A 710, 1-9 (2018).

18. Lainé, S. J. \& Knowles, K. M. Deformation twinning in commercial purity titanium at room temperature. Philos. Mag. 95, 2153-2166 (2015).

19. Kim, H. Y., Wei, L., Kobayashi, S., Tahara, M. \& Miyazaki, S. Nanodomain structure and its effect on abnormal thermal expansion behavior of a Ti-23Nb-2Zr-0.7Ta-1.2O alloy. Acta Mater. 61, 4874-4886 (2013).

20. Liu, J.-P. et al. New intrinsic mechanism on gum-like superelasticity of multifunctional alloys. Scientific Rep. 3, 2156 (2013).

21. Nishiyama, Z., Oka, M. \& Nakagawa, H. \{1011 $\}$ Transformation Twins in Titanium. Trans. JIM. 7, 174-177 (1966).

22. Zheng, Y., Alam, T., Banerjee, R., Banerjee, D. \& Fraser, H. L. The influence of aluminium and oxygen additions on intrinsic structural instabilities in titanium-molybdenum alloys. Scr. Mater. 152, 150-153 (2018).

23. Nii, Y., Arima, T., Kim, H. Y. \& Miyazaki, S. Effect of randomness on ferroelastic transitions: Disorder-induced hysteresis loop rounding in Ti-Nb-O martensitic alloy. Phys. Rev. B 82, 214104 (2010).

24. Ojha, A. \& Sehitoglu, H. Critical Stresses for Twinning, Slip, and Transformation in Ti-Based Shape Memory Alloys. Shap. Mem. Superelasticity 2, 180-195 (2016).

25. Liu, Y. Detwinning Process and Its Anisotropy in Shape Memory Alloys. Proc. SPIE Smart Mater. 4234, 82-93 (2001).

26. Chai, Y.-W., Kim, H. Y., Hosoda, H. \& Miyazaki, S. Self-accommodation in Ti-Nb shape memory alloys. Acta Mater. 57, 4054-4064 (2009).

\section{Acknowledgements}

This work was supported by the Ministry of Trade, Industry and Energy [grant no. 10062485] and the Ministry of Science and ICT [grant no. PNK5700].

\section{Author Contributions}

Sangwon Lee, Chanhee Park, Jaekeun Hong and Jong-taek Yeom contributed to the design and implementation of the research, to the analysis of the results and to the writing of the manuscript.

\section{Additional Information}

Competing Interests: The authors declare no competing interests.

Publisher's note: Springer Nature remains neutral with regard to jurisdictional claims in published maps and institutional affiliations.

Open Access This article is licensed under a Creative Commons Attribution 4.0 International License, which permits use, sharing, adaptation, distribution and reproduction in any medium or format, as long as you give appropriate credit to the original author(s) and the source, provide a link to the Creative Commons license, and indicate if changes were made. The images or other third party material in this article are included in the article's Creative Commons license, unless indicated otherwise in a credit line to the material. If material is not included in the article's Creative Commons license and your intended use is not permitted by statutory regulation or exceeds the permitted use, you will need to obtain permission directly from the copyright holder. To view a copy of this license, visit http://creativecommons.org/licenses/by/4.0/.

(C) The Author(s) 2018 